\title{
Business and Information Systems Engineering Programs at Universities and Fachhochschulen - Convergence or Differentiation?
}

DOI 10.1007/s12599-013-0276-2

\author{
The Authors \\ Prof. Dr. Peter Loos ( $\varangle)$ \\ IWi at DFKI \\ Saarland University \\ 66123 Saarbrücken \\ Germany \\ loos@iwi.uni-sb.de \\ Rosemarie Clarner \\ Prof. Dr. Frank Hermann \\ Prof. Dr. Thomas Hess \\ Prof. Dr. Andreas Gadatsch \\ Prof. Dr. Elmar Sinz
}

Published online: 2013-07-13

This article is also available in German in print and via http://www. wirtschaftsinformatik.de: Loos $P$ (2013) Wirtschaftsinformatikstudium an Universitäten und Fachhochschulen - Konvergenz oder Differenzierung? WIRTSCHAFTSINFORMATIK. doi: 10.1007/s11576-013-0371-5.

(C) Springer Fachmedien Wiesbaden 2013

\section{Introduction}

Business and Information Systems Engineering (BISE) has been offered as study program since the 1970s, both at traditional universities and at Fachhochschulen. German universities have a long tradition and adhere to the Humboldtian principle, in which research and education form a unity.

Fachhochschulen were only introduced in the 1960s in Germany as additional tertiary higher educational institutions. They have also been adopted by other European countries. They focused on practically oriented education; they did not have a research mandate. The Bologna process, intended to create a common European higher education area with undergraduate and graduate programs, seems to eliminate apparent differences between the two types of higher education institutions. Both institutions' study programs last equally long and they award the same degrees (Bachelor and Master). Degrees of Fachhochschulen are legally equivalent to university degrees. Both types of higher education institutions are required to provide graduates' employability. A master's degree from a Fachhochschule in principle qualifies for a Ph.D. program.

Meanwhile, Fachhochschulen are also mandated to application-oriented research. Most Fachhochschulen have changed their names to "Hochschule" and use the English term "University of Applied Sciences".

However, there are still distinct differences. Study programs at Fachhochschulen continue to be much more application-oriented and in general comprise an internship phase, e.g., a practice semester. By contrast, university programs are more theory-oriented. This is also reflected in professors' career paths: for university professors the path is purely academic and requires a Ph.D. and a habilitation or an assistant professorship. In contrast, a Ph.D. and five years of professional practice in industry qualifies for professorship at a Fachhochschule. Furthermore, Fachhochschulen do not have the right to award doctor degrees.

Which consequences result from the similarities and distinctions for the syllabi of business and information systems engineering at the two types of higher education institutions? Professors from universities and Fachhochschulen as well as practitioners were invited to discuss the following questions, among others:

- How do BISE study programs differ in universities and Fachhochschulen? Which similarities do they possess?

- How much practical content should be included in university programs, how much theory should be included in Fachhochschule programs?

- How can the BISE programs be tailored individually at the two types of higher education institutions?
- How should the BISE programs be advanced at the two types of higher education institutions?

- What does the job market expect from the BISE graduates?

The following researchers and professionals have agreed to participate in the discussion (in alphabetical order):

- Rosemarie Clarner, Scheer Group

- Prof. Dr. Andreas Gadatsch, BonnRhein-Sieg University of Applied Sciences

- Prof. Dr. Frank Hermann, Regensburg University of Applied Sciences

- Prof. Dr. Thomas Hess, LMU München (Munich University)

- Prof. Dr. Elmar Sinz, Bamberg University

Rosemarie Clarner, Senior Partner Human Resources with Scheer Group, describes the expectations to BISE graduated applicants from the standpoint of a medium-sized consultancy company.

She believes that the distinctions between universities and Fachhochschulen are increasingly diminishing due to the Bologna process. She prefers education to be related to applications and professional practices, which she sees more often implemented at Fachhochschulen. Thus, she has other priorities regarding expected qualifications than Burkhard Schwenker, who claims a strongly theorydriven syllabus as proper preparation for the business world (Loos et al. 2013). In recruitment processes the type of the applicant's degree is of minor importance, more important are the major fields of studies, international and professional experience, and further skills. All in all she would appreciate a stronger emphasis on imparting social and self-competence in BISE programs.

Frank Herrmann, speaker of the BISE working group at Fachhochschulen (AKWI), considers the transformation of business processes by means of ERP systems as a central theme for many syllabi profiles at Fachhochschulen, supported by the fact that professional experience is a requirement for a Fachhochschule professor. Additionally, theoretical fundamentals and methods are necessary 
to understand the concepts of business application systems.

Thomas Hess, speaker of the Section "Information Systems" (Wirtschaftsinformatik, WKWI) of the German Academic Association for Business Research (VHB), considers theory orientation as an important distinguishing feature of BISE university programs. In our discipline, which is characterized by fast development cycles of business applications, only theoretical knowledge is durable. The theoretical foundations originate in our underlying sciences economics and computer science. Due to the large scope of theory, it is reasonable to start a study program with a selection of theoretical foundations and further extend the theory according to individual topics.

Andreas Gadatsch compares BISE programs at Fachhochschulen and universities by means of their syllabi. He concludes that programs at both types of higher education institutions are structured in a similar way. Differences occur in the stronger orientation towards professional practice at Fachhochschulen and a stronger research orientation at universities. He points out that this should be a distinguishing feature and unique proposition further on. He also requires better possibilities for students to change from one institution type to the other.

Elmar Sinz, who has long-term experience in accreditation processes, states that the number of study programs and the possibility to design an individual study career has increased in both types of higher educational institutions. Similar to Thomas Hess he bases his argument on the half-life period of different knowledge areas in BISE and concludes that theory foundation should be included at an early stage in the programs due to its long-term duration. Only this will allow graduates to adjust to new challenges throughout their professional life. Furthermore, he raises the question why we do not have a straight-through master's program to facilitate a balanced program structure.

Overall, there is a common agreement that differences between the two types of higher education institutions still exist despite the convergence of determining factors imposed by the Bologna process. Differences are mainly seen in practice orientation and theory-centered education. However, assessments diverge regarding their importance in a BISE program. If you would like to comment on this issue - or on any other article in BISE journal - please send your comments (2 pages maximum) to loos@iwi.uni-sb.de.

Prof. Dr. Peter Loos IWi at DFKI

Saarland University, Saarbrücken

\section{The Difference Between German Universities and Fachhochschulen}

As a consulting company which focuses on business process management, we are looking for candidates with degrees in information systems. This subject is offered at German universities as well as at Fachhochschulen. I am often asked whether we have a preference as to universities or Fachhochschulen. To answer this question it is necessary to look at the differences between both types of institutions.

The main aim of universities is to qualify for science and research, although in fact, very few students decide to work as scientists. The main idea of the Fachhochschulen is to qualify graduates to work in business and industry. That, at least, has been the theory until now. However, the differences are becoming increasingly less obvious. As part of the Bologna reforms, universities have become more focused on business and industry, while Fachhochschulen are building on their reputation for being orientated towards business with greater focus on practical research. Students leave both kinds of institution with either bachelor's or master's degrees.

But there are still differences. Fachhochschulen place more emphasis on practice and the transformation of theory into practice and they spend more time on projects and teamwork. This is supplemented with internships and bachelor's and master's theses based on work within companies. All in all, contact to industry is much more pronounced. One reason is the career history of the lecturers. Lecturers at Fachhochschulen must have had a full-time job for at least 5 years, 3 of which in a company in industry. Therefore, they have more work experience, in particular in project coordination and project management. Universities do not have this policy. People with $\mathrm{PhD}$ graduates can directly start as lecturers at universities without any real work experience.
Many Fachhochschulen deal with subjects which are relevant and interesting for business and industry. Therefore, they cooperate very closely with companies. There are Fachhochschulen which have their own offices within companies to support the bachelor's and master's projects more efficiently. Fachhochschulen develop innovative cooperation models, whilst at universities this is comparatively rare. This flexibility is an advantage for the Fachhochschulen, but also means that the amount of theoretical knowledge taught is smaller than at universities. Generally, at universities one third is practice and two thirds theory, and at Fachhochschulen one third is theory and two thirds practice.

Fachhochschulen are more orientated towards the needs of business. This is well demonstrated by the frequency in which new specialized courses come into existence and soon after disappear again.

The lecturers at universities predominantly continue teaching topics which are needed for science and research, i.e., basic science and theory. This teaching is backed up with examples from business and industry, illustrating the theory. However, closer cooperation between universities and companies seems desirable.

Furthermore, it would make sense to teach more social skills at both institutions. These are required in industry and are key recruitment criteria. For example, people need the ability to work effectively and constructively together in project teams; they need communication skills, the ability to listen and to act in a professional manner. We need people who are able to reflect on their own behavior and who are committed to lifelong learning and professional development. We need people who can manage conflicts, can give good presentations, are able to negotiate and know how to convince others. It should not be a difficult task to teach these skills within the system of higher education.

With regards to internationalization, universities are slightly ahead of Fachhochschulen. However, Fachhochschulen are in the process of improving their cooperation with foreign universities, student exchanges and teaching of foreign languages. Universities remain ahead in terms of semesters abroad probably due to the more flexible design of their degree courses.

Universities as well as Fachhochschulen should maintain their own characteris- 
tics but should also aim at approaching one another. There are opportunities to cooperate as well as to use the strengths and to minimize the weaknesses of the respective institutions. However, we have to overcome some obstacles such as arguments over status, as can be seen in the continuing lack of the possibility to award $\mathrm{PhDs}$ at Fachhochschulen. In our company it is not important whether a candidate comes from a university or a Fachhochschule but whether he has a bachelor's or master's degree, what specific qualifications and skills he possesses, if the candidate has done an internship or has experience abroad. In particular it is crucial that the candidate has the required social skills as already mentioned above and brings along creativity, flexibility and very good knowledge of English. Neither do we differentiate between university and Fachhochschule graduates when it comes to starting salaries.

Rosemarie Clarner Scheer Group

\section{Information Systems Engineering in Universities of Applied Science - Practice, Theory and Job Opportunities}

The first complete curriculum for Wirtschaftsinformatik (Business and Information Systems Engineering, BISE) was initiated at the Fachhochschule Furtwangen in 1971. In line with the relevant recommendations of the Gesellschaft für Informatik, the curricula for BISE apply the so called three-column model with classes in information technology, information systems engineering itself, and business administration. As far as I can see this applies both to Fachhochschulen and to universities, enforced also by the unofficial consideration of these recommendations when accrediting the programs. Adhering to the rules of accrediting, specific modules for each class are set for all three areas.

The guiding principle of many concepts can be summarized as the support of processes by information systems. The permeation of many businesses with Enterprise Resource Planning (ERP) systems, especially that of SAP AG, enforces this tendency enduringly. This influence should be relatively high at Fachhochschulen, due to the requirement to have been occupied in business for at least five years before gaining the qualification for a professorship. Further proof is the wide availability of SAP systems at universities and Fachhochschulen; cf. details of the SAP program (SAP University Alliances) on the Internet. All the universities that I know use SAP systems in teaching. Many teachers would justify the relevance of their specific modules by the life cycle of an information system, especially an ERP system. We deal with the stages discovery and evaluation, implementation, turning to productivity ("Go Live”), processing, and continuous improvement - followed by a repetition of these phases. In the stage of implementation, functional requirements like the customization of parameters, the configuration of processes, functional enhancements (also of processes), and interfaces, have to be performed. In contrast, in the process and continuous improvement phase practical technical problems must be solved, such as to cut down on time, to improve the efficiency of the processes, to enhance the integration (especially in reference to data consistency), and to ensure high availability. A generalization of these topics is given in the sections of standard BISE text books, see especially the acknowledged book by Laudon and Laudon (2002) and its translation into German (Laudon et al. 2009). This orientation probably generates a good part of the above-average job opportunities of BISE graduates.

The three columns mentioned above, which normally take up approximately equal room, determine the methods taught. In regard to the IT column, instructions in mathematics and applied logic are not as intensive as in the study programs of general IT, not only due to time restrictions but also owing to the above-mentioned principle. A reference to theory is necessary when transferring this principle to practice, as the whip effect in supply chain management may illustrate. The whip effect shows that orders from suppliers vary more than sales to customers and in doing so deviate from demand, thus, building up ever larger deviations further forward in the supply chain. An improved exchange of information between the parties involved in the supply chain can significantly reduce and even marginalize this whip effect. This (demanding) academic explanation is necessary to prove the potential of additional information and IT is needed to provide it. Many BISE study programs at Fachhochschulen integrate models to explain such concepts.

For quite a few years now, the annual meeting of the working committee BISE at Fachhochschulen ("Arbeitskreis Wirtschaftsinformatik an Fachhochschulen") has comprised a special meeting, where teachers of these institutions present their current research efforts. An overview shows that practical experiences, studies in construction and implementation, especially in ERP systems, have a central role, and, thus, research methods of practical BISE dominate. Besides this design research, explanations are published empirically, often by simulations. For dealing with problems from established areas such as for example Operations Research, customary methods are used. Normally students are coached in the required set of methods in the relevant master classes.

\section{Professor Dr. Frank Herrmann} Hochschule Regensburg

\section{Elements of Theory in BISE Study Programs at Universities}

The higher education system in German speaking countries has undergone a significant differentiation during the last years and decades. Beside universities, we find Fachhochschulen and vocational academies. This development has also influenced business and information systems engineering (BISE). BISE study programs can be found in all of the three types of institutions mentioned above. This kind of differentiation, however, is only useful when the curricula have differing objectives or address different target groups. An important feature of university study programs should be the orientation towards theory. As for all disciplines, the question for BISE is what this theory orientation can look like in concrete terms.

First of all, the question is: why; specifically, why should a practically oriented study program include elements of theory? One answer is self-evident - solution know-how in BISE wears out rather fast. Technologies are subject to permanent improvements; in all areas technological leaps occur every few years. Methodical knowledge has a half-life of only a few years in parts of BISE, considering management methods for example. Theoretical knowledge is much more stable, thus, giving fundamental orientation even decades after graduation. 
Apart from that, one has to consider that BISE, as an academic study program, is constantly competing with other academic disciplines. The development and dissemination of both applicable solutions and theories are constituents of a university. If BISE is to be acknowledged as an academic discipline, it must in no way refuse an orientation towards theory. Other practice-oriented fields, such as engineering or medicine, do not either deny their orientation toward theory; just consider the importance of physics as a basis for engineering or of biological basic knowledge for medicine.

Second, the question is: what; i.e., which theories are relevant for BISE study programs. To begin with, the interdisciplinary character of BISE and, thus, its relationship to both economics and computer science have to be considered. It must be stated that for BISE study programs it is clearly not sufficient to only include topics of practical relevance from economics and computer science. The theoretical foundations of economics (as in the form of microeconomics) or computer science (as in computability theory or in the design of algorithms) should be indispensable elements of BISE programs - omitting them would be fatal for the academic character of a study program. Two different examples may illustrate this. Without profound knowledge of organization theory the phenomenon of outsourcing ITC tasks cannot be substantiated. Similarly, ignorance about the limits of computability will lead to false assessments of the effectiveness of ITC-supported solutions to optimization problems in logistics.

The question on theories original to BISE still remains. It can be approached empirically and normatively. Off the top of his head, the BISE scientist would say that an autonomous subject like BISE also needs an autonomous theory. In practice this is not so currently. Lim et al. (2009) have clearly shown that information systems research (ISR) typically makes use of economic theories or the underlying theories of behavioral sciences. A similar examination of BISE would probably show computer science and possibly mathematics as additional sources for theories - this would not change the fundamental conclusion. The same goes for the known exceptions, as for example the acceptance theory strongly pushed by both ISR and BISE. The conclusion remains that BISE normally uses theories of related fields. By the way: perhaps this is not bad at all. Possibly, the contribution of BISE lies in supporting the "mother disciplines" and building a bridge between them.

Finally, the question when has to be answered: at which point should theoretical elements be included in higher BISE education? The typical academic approach would be to begin with theories and proceed to up-to-date practical solutions. Basically, this goes for BISE as well. The necessary width of the theoretical approach from two disciplines, however, makes it difficult to keep up with this requirement. The only pragmatic approach is to selectively teach some theoretical foundations from economics and computer science in the beginning of undergraduate studies with later amendments according to individual issues. Typical examples are digital products. Even though the economic characteristics of digital products are most certainly not part of the standard economic foundations of BISE, no understanding of digital products and services is possible without a thorough understanding of direct or indirect net effects.

Prof. Dr. Thomas Hess LMU München

Speaker of WKWI 2011-2013

\section{Characteristics and Profiles of Study Programs for BISE at Universities and Fachhochschulen}

\subsection{Differences and Common Features}

The change for Bachelor and Master programs has incurred a restructuring of curricula. Business and information systems engineering (BISE) studies are offered in various ways. Independent programs for bachelors and masters are of fundamental significance. Here, the independent program for bachelor students of BISE is looked at as it is in the center of professional education.

In Tab. 1, arbitrarily selected features of two study programs (University of Applied Science Münster and University of Cologne) are shown. Unfortunately, no applicable CHE-rankings are available to give orientation for a better choice (CHE 2013). The choice was therefore based on a Google search with the keywords "studium wirtschaftsinformatik fh" and "studium wirtschaftsinformatik uni", conducted on 2013-04-04. The first non-sponsored links were used.
Aspects of workload were not taken into consideration due to time considerations.

The curricula are constructed similarly; differences however can be found in the details. The aim for fundamentalsoriented education to provide job opportunities as well as formal aspects (duration of studies, final examinations, and colloquia) can be considered as the main common features. Basically, both programs offer central elements of computer science, business studies, economics, BISE, and a classical cross section from the areas of mathematics, statistics, and law. In addition, students have to write a thesis in connection with a colloquium. Electives at the University of Cologne are more differentiated than those at the Fachhochschule Münster. Cologne offers an integrated "Studium generale" and further elective areas to enable individual study profiles. At the Fachhochschule Münster obligatory elements of practice are more prominent.

For comparison, two further examples were selected (HTW Berlin and University Koblenz-Landau), not shown here for space reasons. Even more similarities could be observed. Only very few differences can be recognized, for example, as above, in the design of practiceoriented parts. This noticeable harmonization in both cases is probably due to the "Rahmenempfehlung für die Universitätsausbildung in Wirtschaftsinformatik" (Basic recommendation for academic education in BISE) (WKWI 2007), which considerably molded the development of study programs at Fachhochschulen.

\subsection{Necessary Know-How in Practice and Theory}

Education in BISE is method oriented. Fast changes in practice are followed by equally fast changes in study programs (Mertens 2006). Practice knowhow should be taught for exemplary description and revision of methodical knowledge only. Preference has to be given to know-how for long-term use. The use of software products should not be in the foreground.

\subsection{Profiling Options}

The scope for differentiation between the two, already converging, types of higher education is limited, as both degrees grant professional qualifications. 
Table 1 Bachelor Study Programs for BISE (Fachhochschule Münster 2013 and Universität zu Köln 2013)

\begin{tabular}{|c|c|c|}
\hline School & Fachhochschule Münster (FH) & University of Cologne \\
\hline Degree & Bachelor of Science & Bachelor of Science \\
\hline Duration & 6 semesters & 6 semesters \\
\hline \multirow[t]{2}{*}{ Aim } & Impart fundamentals & Impart fundamentals \\
\hline & $\begin{array}{l}\text { Immediate employability (e.g., as software developer, } \\
\text { analyst, consultant, independent of specific industries) }\end{array}$ & $\begin{array}{l}\text { Immediate employability (in different industries with } \\
\text { double qualification in management and computer } \\
\text { science) }\end{array}$ \\
\hline \multirow[t]{2}{*}{$\begin{array}{l}\text { Management/ } \\
\text { economics }\end{array}$} & Fundamentals of business administration, economics & $\begin{array}{l}\text { Compulsory modules: balance sheets, management } \\
\text { accounting, accounting techniques }\end{array}$ \\
\hline & Primary business processes & $\begin{array}{l}\text { Numerous optional classes from management and } \\
\text { economics }\end{array}$ \\
\hline $\begin{array}{l}\text { Computer } \\
\text { science }\end{array}$ & $\begin{array}{l}\text { Operating systems, computer architecture, software } \\
\text { development I/II, web-development I/II, computer } \\
\text { networks, web-engineering }\end{array}$ & $\begin{array}{l}\text { Computer science } \mathrm{I} / \mathrm{II} \text {, programming class, programming } \\
\text { lab }\end{array}$ \\
\hline \multirow[t]{2}{*}{ BISE } & BISE fundamentals, programming fundamentals & $\begin{array}{l}\text { Compulsory modules: integrated IS, database systems, } \\
\text { management of IS project }\end{array}$ \\
\hline & $\begin{array}{l}\text { Business application systems I/II, business engineering, } \\
\text { business intelligence }\end{array}$ & $\begin{array}{l}\text { Four optional modules: systems development, database } \\
\text { systems, data usage with decision problems, information } \\
\text { management, etc. }\end{array}$ \\
\hline Comprehensive & $\begin{array}{l}\text { Business mathematics, statistics, commercial law, } \\
\text { quantitative methods, English }\end{array}$ & $\begin{array}{l}\text { Mathematics, probability calculus and statistics, } \\
\text { commercial law (optional) }\end{array}$ \\
\hline $\begin{array}{l}\text { Core elective } \\
\text { classes }\end{array}$ & Two core elective classes, catalog of eight choices & $\begin{array}{l}\text { Very extensive selection, also from related sciences, special } \\
\text { clusters allow for individual focus, e.g., finance, health care } \\
\text { management }\end{array}$ \\
\hline Thesis & Bachelor thesis with colloquium & Bachelor thesis with colloquium \\
\hline $\begin{array}{l}\text { Practice } \\
\text { integration }\end{array}$ & $\begin{array}{l}\text { Practice phases of three and six months at the end of the } \\
\text { studies }\end{array}$ & Programming practice \\
\hline
\end{tabular}

The advantages of Fachhochschulen in application, adaption, and applicationoriented improvements in methods and theory should be extended. The smaller sizes of study groups already support this model. Universities can expand their competencies in the development of fundamental theories and methods. Overlapping is desirable to enable permeability. In no case should changes from one system to the other be obstructed.

Fachhochschulen can strengthen their profiles by practice-oriented classes with the focus on methods application. Universities can exploit their potential for larger research activities.

\subsection{What Does the Job Market Expect from Graduates?}

Graduates basically face identical requirements. They have to be able to solve demanding technical and organizational problems independently in volatile surroundings. They need solid theoretical knowledge but also the capability to employ their methodical know-how when confronted with concrete practical prob- lems. Requirements regarding the study content or the school type are often quite abstract in job advertisements in order to address all potential applicants. A typical example is "We expect a degree in Computer Science, BISE, Mathematics or a degree in Management, Economics, Business and Engineering, or similar studies" (Abracon 2013). Obviously, BISE is competing with other degrees. Later on in a career, personal involvement, applicable special know-how, competencies in leadership and communication, and permanent professional training (for example in off-the-job master programs) are decisive for further success.

\subsection{Conclusion}

The strength of Fachhochschulen lies in the intensive integration of practice elements. Universities can accentuate research.

Prof. Dr. Andreas Gadatsch Hochschule Bonn-Rhein-Sieg

\section{Characteristics and Profiles of Business and Information Systems Engineering Programs at Universities and Fachhochschulen}

Previously students used to have two options: university or Fachhochschule. A university was attended by those who wanted to do it thoroughly, who possibly were apt for a later promotion, or who were drawn in this direction by their family background. A Fachhochschule was chosen by those who wanted to graduate quickly and at low risk, and who in any case planned to enter a professional career path afterwards.

With the Bologna process, the decision situation for prospective students has become more diverse, but not simpler. Universities as well as Fachhochschulen offer bachelor and master degree programs, both of which are required to lead to a professional qualification. Access to a master's degree requires a professional degree, usually a bachelor. The student is guided closely in both types of study programs, he completes modules which usually are accomplished within 
one semester and have ECTS points $($ ECTS $=$ European Credit Transfer and Accumulation System) attached as a volume measure, and with a grade as a performance measure. The student can decide whether he pursues his bachelor and master degree at one type of higher education institution, whether he finishes his studies after the bachelor and uses the professional qualification to go into practice, whether he takes the bachelor's degree at a Fachhochschule and changes to a university for the master or vice versa. $\mathrm{He}$ may take up a $\mathrm{PhD}$-program in either case, because in this context a Fachhochschule master is considered formally equal to a university degree. The syllabi contain degrees of freedom, such as bachelor programs with 6 to 8 and corresponding master programs with 2 to 4 semesters. Here some strange variations are coming into existence, such as "fast tracks" for doctoral students.

When searching for information regarding the specific duties beyond the political will (Fachhochschulen now are called Universities of Applied Sciences or Universities in short, the awarded degrees do not provide a clue as to the type of higher education institute), a look at legislation is helpful. For example, the Bavarian Higher Education Act (Bayerisches Hochschulgesetz 2012) lays down in article 2 (duties): "The universities are mostly devoted to research and teaching and connect these to a predominantly science-related education" (translation by author). And on the other hand: "By means of an application-oriented lecture program, Fachhochschulen provide education that enables the independent application of scientific methods and artistic activities in professional practice; in this context they perform application-oriented research and development". Thus, the difference in the duties of the two types of higher education institutions is sciencerelated education versus education for the independent application of scientific methods.

At this point, the area of business and information systems engineering (BISE) comes into play. Assuming that the halflife of theoretical knowledge is 15 years, that of methodical knowledge is 5 years, that of product knowledge (not practical knowledge!) is 6 months, and that the duties of the higher education institutions are interpreted literally, the following questions arise:

- When should the theoretical foundations of BISE be taught best in the curriculum?

Starting with the first semester! Here, the structures of the discipline are laid and the basic classifications are built. Students will be coined for the subject area.

- Why is there no single-tier master in BISE?

This is one of the design flaws in the implementation of the Bologna process. A single-tier master's program would solve the problem of science-related (basic) education, avoid the cramped attempt for a professional qualification of the bachelor, be understood internationally and save students time (elimination of the bachelor thesis, elimination of friction in the transition between bachelor and master).

- Do students who have obtained a Fachhochschule bachelor's degree face unreasonable difficulties in a university master's degree program in BISE?

Yes, in principle they do. But at least it is generally the most motivated bachelor graduates who go to the master's program at the university, and neither the Fachhochschulen nor the universities generally cling overly to their specific duties. Nevertheless, arrangements have been made for this case, e.g., at the university of Bamberg, by allowing to transfer up to 12 ECTS-points from the bachelor program to the master program in reasonable cases and upon application.

Today we prepare our graduates for a professional life of 44 years (18 years through high school, 5 years of study, and retirement at the age of 67). We do not know what awaits us in a dynamic field like BISE in 5 and 10 years. Would it not be indicated to train as many young people as possible on a science basis and, thus, enable them to autonomously adapt to the unknown and create something new? "There is nothing as practical as a good theory", this statement by the social psychologist Kurt Lewin is of continuing importance also now.

$$
\begin{array}{r}
\text { Prof. Dr. Elmar J. Sinz }{ }^{1} \\
\text { Universität Bamberg }
\end{array}
$$

\section{References}

\section{to: Section 1}

Loos $\mathrm{P}$, Mertens $\mathrm{P}$, Eymann $T$, Hirschheim $\mathrm{R}$, Schwenker B, Hess T (2013) Qualification profile of university professors in business and information systems engineering. Bus Inf Syst Eng 5(2):107-114

\section{to: Section 3}

Laudon JP, Laudon KC (2002) Management information systems: managing the digital firm, 7th edn. Prentice Hall, Upper Saddle River

Laudon JP, Laudon KC, Schoder D (2009) Wirtschaftsinformatik: Eine Einführung, 2nd edn. Pearson, München

\section{to: Section 4}

Lim S, Saldanha T, Malladi S, Melville NP (2009) Theories used in information systems research: identifying theory networks in leading IS journals. In: Proc ICIS 2009, Phoenix, paper 91

\section{to: Section 5}

Abracon $\mathrm{GmbH}$ (2013) Stellenangebot SAP NetWeaver BI/BW Juniorberater (w/m). http://www.abracon.de/sap-netweaver-bibw-juniorberater-wm.html. Accessed 2013-04-02

CHE (2013) CHE Hochschulranking 2012/13. http://ranking.zeit.de/che2012/de/ fachinfo? esb=2. Accessed 2013-04-04

Fachhochschule Münster (2013). Wirtschaftsinformatik (Bachelor). https://www. fh-muenster.de/studium/studiengaenge/ bachelorstudiengaenge.php. Accessed 2013-04-04

Mertens P (2006) Moden und Nachhaltigkeit in der Wirtschaftsinformatik. Arbeitspapier Nr 1, 2006, Universität Nürnberg-Erlangen. http://www.wi1-mertens.wiso.unierlangen.de/veroeffentlichungen/suche. php?typ=arbeitsberichtwii\&order $1=$ autoren\&ascdesc $1=$ asc\&order2 = titel\&ascdesc2=asc. Accessed 2013-03-21

Universität zu Köln (2013) Wirtschaftsinformatik (Bachelor). http://www.wiso.unikoeln.de/14714.html. Accessed 2013-0404

WKWI (2007) Rahmenempfehlung für die Universitätsausbildung in Wirtschaftsinformatik. Von einer Fachkommission im Auftrag der Wissenschaftlichen Kommission (WK) Wirtschaftsinformatik im Verband der Hochschullehrer für Betriebswirtschaft erarbeitet; von der WK am 1.3.2007 und vom Präsidium der Gesellschaft für Informatik am 28.6.2007 genehmigt pp 2013-03-2013-21. http://fbwi.gi.de/fileadmin/gliederungen/fb-wi/wiempf-2007.pdf. Accessed 2013-03-21

\section{to: Section 6}

Bayerisches Hochschulgesetz (2012) May 23, 2006, amended July 9, 2012

\footnotetext{
${ }^{1}$ For eight years the author chaired the technical committee BISE at the accreditation agency ASIIN, and for eight years he was member of the technical committee on Computer Science+ at ACQUIN.
} 